\title{
Dialogando no rádio com agricultores sobre o cuidado com o solo para promover sistemas agroalimentares sustentáveis
}

\author{
Maicon Miguel Vieira da Silva ${ }^{1}$, Rayana Minervino Leite ${ }^{2}$, Rodrigo Silva de Moura ${ }^{3}$, Mateus Procópio da Silva ${ }^{4}$ Eliel \\ Gomes Barbosa ${ }^{5}$, Adriana de Fátima Meira Vital ${ }^{6}$ \\ Universidade Federal de Campina Grande; ${ }^{1}$ maicon.agroecologia@gmail.com; ${ }^{2}$ minervinorayana@gmail.com; \\ rodrigosilva12363@gmail.com; ${ }^{4}$ mattheusw33@ hotmail.com; ${ }^{5}$ barbosa.eliel@outlook.com; \\ vital.adriana@ufcg.edu.br.
}

\begin{abstract}
RESUMO: Na tentativa de consolidar a comunicação rural como instrumento de diálogo do povo camponês com a sociedade, valorização da agricultura familiar, promoção das tecnologias fundamentadas na agroecologia, centradas na conservação do solo e na sustentabilidade dos sistemas agroalimentares, utilizando as potencialidades do suporte do rádio, o Programa Matutando Agroecologia, inaugurou em março de 2018 a exibição da live via rede social Facebook, servindo como espaço de debates e laboratório para a comunicação popular através da internet. Para atingir os objetivos, o programa é produzido, editado e apresentado por estudantes da UFCG campus CDSA (Sumé PB) com a supervisão da coordenação do Programa de Ações Sustentáveis para o Cariri (PASCAR). A partir das edições via live tem sido possível oportunizar aos agricultores familiares a expressão de opiniões, a divulgação do seu modo de vida e de seus interesses, além de contribuir para divulgar os princípios da agroecologia e dos resultados de pesquisas que não chegam aos camponeses. Desse modo, este trabalho objetiva relatar a experiência do programa e o crescimento da audiência entre os agricultores em função do uso da internet como facilitador do processo de construção do conhecimento agroecológico.
\end{abstract}

PALAVRAS-CHAVE: Comunicação rural; Radiodifusão; Educomunicação; Internet.

\section{INTRODUÇÃO}

A comunicação é um poderoso meio de informação, além de servir como um elemento básico de interação, compartilhamento de conhecimentos, ajudando a criar um conjunto de ideias, fortalecendo o sentimento de união através da troca de mensagens e da tradução de pensamentos em ações.

A informação é um ponto chave para todas as atividades humanas, independentemente do campo; seja turismo, saúde, educação, agricultura etc. Por esse motivo, a informação é considerada um recurso vital que precisa ser desenvolvido adequadamente, devido ao seu vasto efeito na sociedade (IJAH, 2013). Não é inapropriado afirmar que uma sociedade que não prima pela comunicação e informação fica atrás de outras que possuem infraestrutura de informação eficientes (MOEMEKA, 1985).

Como a agricultura desempenha um papel importante no desenvolvimento da economia das cidades com impacto no crescimento econômico, na geração de renda das famílias e na segurança alimentar, é fundamental o fortalecimento das atividades de comunicação rural, para que os agricultores se inteirem das novas possibilidades para agregar sustentabilidade à produção e com orientações sobre o cuidado com suas área de produção e o estabelecimento de práticas que potencializem a sustentabilidade dos sistemas agroalimentares. É imprescindível dedicar mais atenção no processo de comunicação para fornecer aos cidadãos acesso à informação, especialmente nas áreas rurais onde vive grande parte da população de alguns ambientes do Brasil.

A radiocomunicação é um veículo de educação dos cidadãos sobre diversas questões inerentes à sociedade. O rádio serve como um agente de mobilização social; as pessoas são movidas a atingir um determinado objetivo, com base na conscientização de seus direitos e responsabilidades perante a sociedade.

Por ser amplamente utilizado em diferentes regiões, o rádio se tornou um meio valioso de comunicação e disseminação de informações, bem como de treinamento e educação para amplos segmentos de comunidades rurais (ZIJP, 2003).

Marcado pela proximidade com os ouvintes, prestação de serviços, baixo custo e mobilidade de recepção e pela presença de suas ondas em regiões remotas, o rádio é o instrumento de comunicação mais democrático e o principal veículo de informação, especialmente nas regiões mais distantes e nos ambientes campesinos. E quando se pensa particularmente na atividade agrícola, a relevância da informação aumenta.

A proposta de aliar um programa radiofônico às novas possibilidades das tecnologias pode resultar em ganhos importantes para as comunidades rurais, especialmente por trabalhar a proposta da inclusão e visibilidade.

Com as novas tecnologias de comunicação - especificamente a internet, a oferta de informação tem aumentado significativamente, diluindo a noção de distâncias, diminuindo a lacuna existente entre uma parcela da população que historicamente sempre esteve, à parte do processo de integração global (GAMEIRO \& GAMEIRO, 2004).

Nesse cenário foi proposto o Programa Matutando Agroecologia, que teve seu nascedouro a partir de diálogos com feirantes e agricultores familiares e pretende estimular a interatividade ouvinte - locutor estudante, sendo o ouvinte e coparticipante o agricultor familiar da cidade de Sumé e região.

Caderno Verde de Agroecologia e Desenvolvimento Sustentável (ISSN 2358-2367) v. 9, n.7, e-6987, 2019 doi: 10.18378/cvads.v9i7.6987 
SILVA, M. M. V. et al. Dialogando no rádio com agricultores sobre o cuidado com o solo para promover sistemas agroalimentares sustentáveis. In: II Congresso Paraibano de Agroecologia \& IV Exposição Tecnológica, 2019. Anais... Caderno Verde de Agroecologia e Desenvolvimento Sustentável, Pombal, v. 9, n.7, e-6987, 2019.

O programa, em sua concepção, incorpora a perspectiva da promoção da autonomia e protagonismo das mulheres agricultoras e dos jovens rurais, contribuindo para dar visibilidade ao processo de transição agroecológica no território do Cariri paraibano. Além de informações técnicas, onde são divulgados os resultados de pesquisa e experiências em agroecologia, depoimentos e entrevistas, o programa também veicula música e outras formas de manifestação da cultura popular, favorecendo a construção conceitual da relação entre o trabalho, ciência, cultura, tecnologia.

A proposta do programa busca também articular a pesquisa e a extensão por meio da prática na utilização da comunicação para possibilitar aos estudantes um meio de interação com o povo do campo, preparando-os para o exercício profissional na extensão rural centrada no conhecimento agroecológico, desenvolvendo habilidades e lhes permitindo atuar como facilitadores do processo de construção do conhecimento.

Com a disseminação das redes sociais, os estudantes que conduzem o Matutando trouxeram a proposta de fazer ao vivo suas apresentações, nas lives dos domingos, de maneira a permitir maior participação dos ouvintes, em sua maioria agricultores.

O presente trabalho objetiva investigar o grau e as formas de identificação dos agricultores com o Programa Matutando Agroecologia e verificar se existe ou não aplicabilidade das informações nele veiculadas a partir das apresentações na rede social Facebook.

\section{MATERIAL E MÉTODOS}

A equipe do Programa Matutando Agroecologia é composta por um docente, um estudante do curso de Tecnologia em Agroecologia, bolsista do Programa de Ações Sustentáveis para o Cariri (PASCAR), uma estudante do curso de Engenharia de Produção, todavia, mais dois estudantes estão sendo preparados, e há docentes apoiadores do campus e outros profissionais externos.

O programa é produzido, editado e apresentado por estudantes da UFCG campus CDSA (Sumé PB) com a supervisão da coordenação do Programa de Ações Sustentáveis para o Cariri (PASCAR) e é veiculado pela Rádio Cidade de Sumé (95 FM), aos domingos, do meio dia e meia às treze horas, sem ônus pra universidade.

Para o desenvolvimento e execução da proposta metodológica a equipe envolvida na realização do Programa Matutando Agroecologia visita semanalmente a feira para dialogar com os agricultores e elaborar os textos com temas relacionados a agroecologia, campesinato e conservação do solo.

Trabalham-se os temas técnicos, mas a equipe de produção do Matutando desenvolve temas da regionalidade e da cultural nordestina, trazendo músicas de grandes nomes do forró, dos versos e dos repentes.

Figura 1. Exibição do Matutando Agroecologia na rede social Facebook, na 95 FM de Sumé-PB.

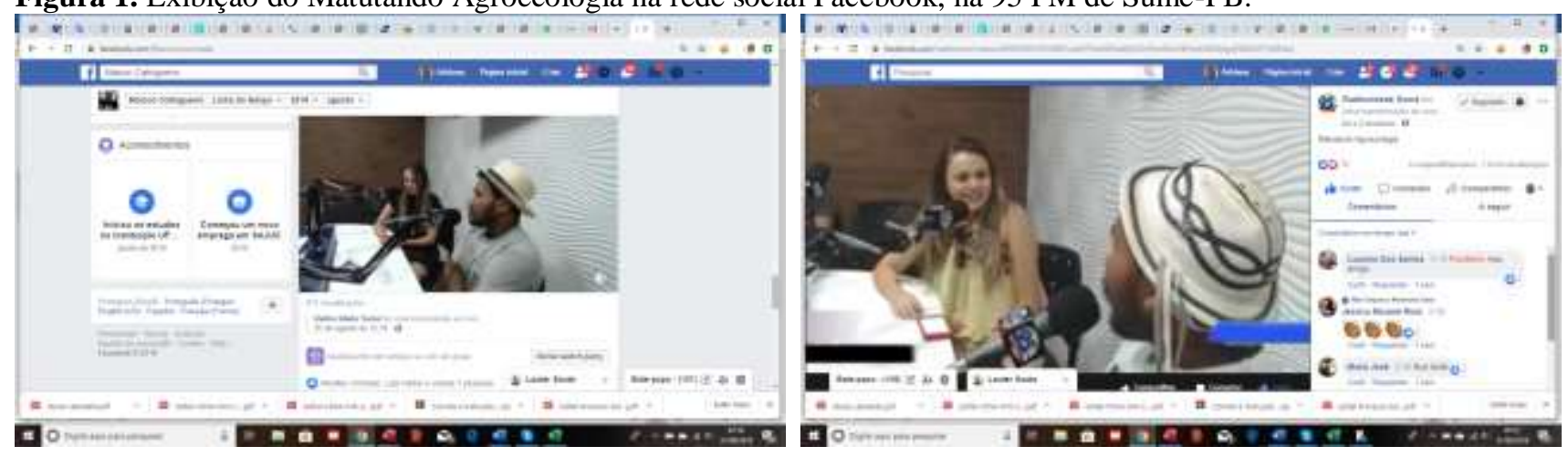

As entrevistas são outro ponto forte do Matutando, sendo produzidas tanto nas feiras ou nos roçados, com chamadas ao vivo durante o programa como também de forma presencial, buscando sempre a equidade de gêneros na escolha dos entrevistados.

A ideia central das entrevistas é promover o diálogo de saberes entre os apresentadores com os povos do campo fazendo com que haja um diálogo entre o que é teorizado dentro da academia e o que é praticado no meio rural.

As receitas da culinária regional também estão presentes no Matutando Agroecologia, no entanto a um recorte com os alimentos produzidos a partir de derivados da Caatinga a exemplo do umbu.

O programa vai ao ar aos domingos, pela 95 FM (Radio Cidade de Sumé) do meio dia e meia às treze horas sendo transmitido via live pela rede social Facebook.

\section{RESULTADOS E DISCUSSÃO}

Desde 2012 o Programa Matutando Agroecologia está no ar e tem se consolidado como um dos programas líderes em audiência da 95 FM Radio Cidade, pois tem sido um instrumento atrativo para os amantes do rádio, abraçando um horário que normalmente era dedicado apenas a exibição de músicas. 
SILVA, M. M. V. et al. Dialogando no rádio com agricultores sobre o cuidado com o solo para promover sistemas agroalimentares sustentáveis. In: II Congresso Paraibano de Agroecologia \& IV Exposição Tecnológica, 2019. Anais... Caderno Verde de Agroecologia e Desenvolvimento Sustentável, Pombal, v. 9, n.7, e-6987, 2019.

No entanto havia ainda um distanciamento do público maior do programa - agricultores e agricultoras - com a equipe do Matutando Agroecologia, uma vez que as proposições dos temas era construído nas visitas que se davam no ambiente interno da UFCG ou na cultural feira da cidade, que além de ser um ponto de comercialização de bens e produtos é também um ponto de encontro e confraternização, mas não deixava espaço para integração entre todos, inclusive para perceber como o programa chegava e como era a percepção dos ouvintes.

A partir de 2018 foi inserido na proposta metodológica do Matutando a realização da transmissão via live do Facebook. Esse processo teve como principal objetivo a promoção da aproximação e o fortalecimento do diálogo entre os ouvintes, uma vez que esta ferramenta possibilita "criar cenários de comunicação, com elevado nível de interação, com grande riqueza informativa, cognitiva e emocional" (RAMOS et al, 2012, p.225).

O Facebook foi criado a pouco menos de vinte anos e é hoje a rede com a maior quantidade de usuários do mundo (ROSS, 2014), reunindo em um mesmo espaço virtual a possibilidade de interação com os usuários e a exposição de diferentes histórias.

Por meio da live tem sido possível à equipe dialogar com os ouvintes durante a transmissão nos comentários, o que se dá em tempo real. Para além disso os internautas ouvintes que por algum motivo não acompanharam o programa ao vivo, terão a oportunidade de assistir ao Matutando em momento posterior sem prejuízo no processo de interação com as pautas o que não é possível sem a utilização deste recurso (live). Ressalta-se que a inserção desta ferramenta não inviabilizou as demais ferramentas utilizadas, como chamadas telefônica e a interação pelo o Whats App.

A forma interativa com que é pensando o programa, bem como a participação dos ouvintes tem sido a marca registrada do Matutando, o que é bastante perceptível quando os apresentadores estão nas ruas da cidade e são reconhecidos pelas pessoas, sobretudo na feira da cidade.

A interação dos internautas ouvintes acontece nos comentários e por meio de pedido de músicas e poesias, ou mesmo registro do tradicional "alô", como também na solicitação de temas, sugestão de receitas e até mesmo a sugestão de objetos que podem ser usados a exemplo de chocalhos.

Figura 2. Realização de entrevistas durante o Matutando Agroecologia na 95 FM de Sumé-PB.
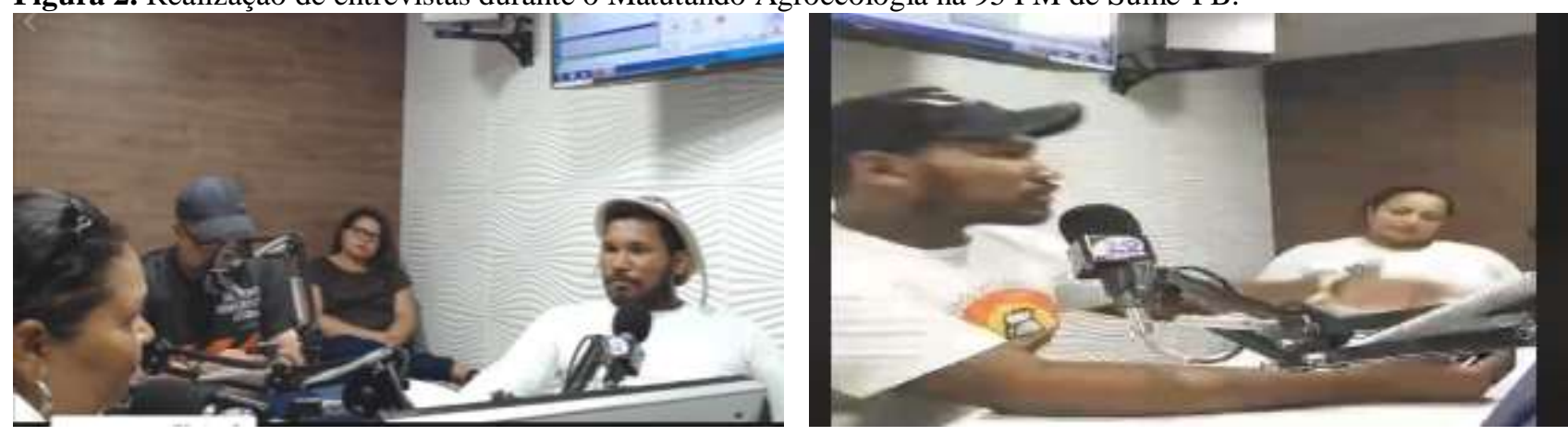

Trabalham-se os temas técnicos, mas a equipe de produção do Matutando tem a preocupação em desenvolver temas da regionalidade e da cultural nordestina, trazendo músicas de grandes nomes do forró como, Flavio José, Santanna e Luiz Gonzaga, bem como a invocação de alguns prefixo sertanejo na abertura do programa na interação do apresentadores a exemplo do famoso "Ô de Casa? Quem é? Ô de casa? Quem é? É o Matutando Agroecologia pedindo licença para entrar na sua casa". Como também no encerramento do programa com os dizeres "Louvado seja Nosso Senhor Jesus Cristo, para sempre seja Deus Louvado e Tchau, Brigado".

Outro recurso que bastante explorado é a poesia regional sendo realizados o esforço para apresentar poesia que contextualizem com o tema bem como poesias que dinamizem o programa nesse sentido é utilizado obras de grandes nomes da poesia nordestina como Pinto do Monteiro, Braulio Bessa e Jessiê Quirino bem como a produção de poesia por partes dos apresentadores conforme exemplo a seguir.

Matuto no mêi da Pista
Minino Chorando Nu
Rôlo de fumo e bejú
Colchão de palha listrado
Um par de bêbado agarrado
Um preto véi rezador
Jumento, jipe e trator
Lençol voando estedido
Isso é cagado e cuspido
Paisagem do interior
Jêssie Quirino

Agroecologia está presente

Na produção camponesa

Que chega em nossa mesa

E deixa a todos contente

Pois é um modo diferente

Uma cultura alimentar

Que veio pra saciar

O campo e a cidade

Com comida de verdade

Produzida no lugar

Maicon Caatingueiro 
SILVA, M. M. V. et al. Dialogando no rádio com agricultores sobre o cuidado com o solo para promover sistemas agroalimentares sustentáveis. In: II Congresso Paraibano de Agroecologia \& IV Exposição Tecnológica, 2019. Anais... Caderno Verde de Agroecologia e Desenvolvimento Sustentável, Pombal, v. 9, n.7, e-6987, 2019.

Uma particularidade do Matutando é que através dos quadros inseridos desde os diálogos promovidos nas feiras e nas visitas aos roçados, como as dicas de receitas, é que é possível trabalhar as questões de gênero uma vez que as receitas são preparadas e apresentadas de forma intercalada entre os apresentadores com intuito de desmitificar a ideia de que só mulheres cozinha mas também que o homem podem ocupar lugar central na cozinha.

O Matutando Agroecologia tem conseguido, ao longo dos anos, trazer o camponês para fazer uso dos veículos que comunicação apesar de todo o monopólio que dominam os meios midiáticos, no entanto, mostrando a importância de não abrir mão dessas experiências de democratização da mídia.

Por meio da realização da live houve uma ampliação dos ouvintes do programa, uma vez que a Rádio Cidade tem seu raio de alcance em torno de 40 cidades em três estados sendo Paraíba, Rio Grande do Norte e Pernambuco, a transmissão do programa pelo o Facebook e consequentemente usando as ondas da internet, rompe qualquer barreiras territorial sendo o matutando um programa com dimensões global.

Em um recorte nacional percebemos que o Matutando conseguiu através da live do Facebook um inserção maior nos estados de Minas Gerais, Rio de Janeiro, Bahia e São Paulo que ocorrem para além das ondas de transmissão da Rádio Cidade, fazendo com que haja um aumento significativo na audiência do programa no entanto sendo o mais importante o aumento do público alvo e consequentemente a ampliação do diálogo sobre as questões relacionadas à conservação e educação em solos e agroecologia.

Desde a implantação das lives no Matutando Agroecologia aumentou consideravelmente a audiência da 95 FM, sobretudo no grande número de visualizações do programa. Importa reconhecer que essa proposta é diferenciada pelo caráter de popularização da ciência e pela valorização do povo do campo, sem falar na interação ouvinte-rádio que foi completamente transformada, tornando o ouvinte um integrante ativo e participativo nas emissoras, ampliando as possibilidades de aproximação e veiculação de temas, sendo assim, como argumenta Prata (2012) nessa constelação de elementos sonoros, textuais e imagéticos, uma oportunidade feliz de inovação que amplia a interatividade e o empoderamento pela facilidade de participação.

\section{CONCLUSÕES}

A inserção das lives no Programa Matutando Agroecologia tem se constituído como uma importante ferramenta para a difusão de práticas agroecologia no meio rural, bem como somar uma significativa contribuição para o empoderamento camponês no tocante as questões sociais e práticas agroecológica.

A presença do publico alvo (camponeses) durante a apresentação do programa fortalece o processo de comunicação popular com os internautas camponeses e demais ouvintes.

$\mathrm{O}$ acesso a internet aliada ao desenvolvimento de atividades ligadas as redes de comunicações privada destaca-se como uma importante ferramenta bem como um processo importante para a democratização dos veículos e atividade midiáticas.

Para além disso, ressalta-se que o ciberespaço é de fato uma possibilidade para aprimorar a aproximação de saberes e fortalecer a construção do conhecimento agroecológico, pela perspectiva de atuar na prestação de serviço e extensão de conteúdos que se integram através de várias áreas de conhecimento, atingindo um público que até pouco tempo viva na exclusão, distante das inovações produzidas pela ciência.

Pela observação dos pontos positivos dessa aproximação, apontada pelo trabalho, percebe-se que o crescimento da radiofonia na web aponta a importância de se investir numa programação, cujos conteúdos sejam voltados ao público do campo, contribuindo para a informação e formação social. Além disso, a proposta é também uma ferramenta de extensão que pode promover a troca de saberes e socialização de informações técnicas da comunidade de pesquisa agrícola em geral, incluindo universidades, institutos de pesquisa e extensão e organizações não-governamentais para os camponeses.

Diante das observações sugere-se que os programas de rádio voltadfos para o povo camponês sejam potencializados, assim como o uso das lives nas redes sociais, como meio de comunicação para a difusão de informações agropecuárias, tanto técnicas quanto de valorização da cultura e tradição.

\section{REFERÊNCIAS}

GAMEIRO, M.B.P.; GAMEIRO, A.H. O rádio no desenvolvimento socioeconômico da agricultura: uma alternativa ao processo de exclusão na era da internet. Anais. XLIII Congresso Brasileiro de Economia e Sociologia Rural. CD-ROM. Cuiabá: SOBER, 2004.

IJAH, A. Radio as a Tool for Rural Development in Nigeria: Prospects and Challenges. An International Journal of Arts and Humanities Bahir Dar, v. 2, n.1, p. 2-3. 2013.

PRATA, N. WEBRADIO: novos gêneros, novas formas de interação. Florianópolis: Insular, jan.2012. 
SILVA, M. M. V. et al. Dialogando no rádio com agricultores sobre o cuidado com o solo para promover sistemas agroalimentares sustentáveis. In: II Congresso Paraibano de Agroecologia \& IV Exposição Tecnológica, 2019. Anais... Caderno Verde de Agroecologia e Desenvolvimento Sustentável, Pombal, v. 9, n.7, e-6987, 2019.

ROSS, M. Facebook turns 10: the world's largest social network in numbers. ABC news, Sydney, 04 Fev. 2014. Disponível em: http://www.abc.net.au/news/2014-02- 04/facebook-turns-10-the-social-network-in-numbers/5237128 Acesso: 20/08/2019.

MOEMEKA, A. Local Radio Communication Education for Development. Zaria: ABU Press. 1985.

ZIJP, W. Improving the transfer and use of agricultural information: a guide to information technology. Washington DC: World Bank. World Bank Discussion Paper No. 247. 2003.

\section{AGRADECIMENTOS}

Apoio financeiro: Fundação de Apoio à Pesquisa do Estado da Paraíba - FAPESQ. 